\title{
EFFECTS OF PURE AND FAKE HONEY ON GLUCOSE AND LIPID PROFILE in vitro AND in vivo STUDY
}

\author{
MUHAMMAD FAIZ ZULKIFLI ${ }^{1}$, SUHANA SAMAT ${ }^{2}$, NURUL SHAHIRAH MOHD AZAM ${ }^{1}$, \\ FRANCIS KANYAN ENCHANG ${ }^{2}$, ABDULLAH ABD RAZAK $^{2}$, FUZINA NOR HUSSEIN ${ }^{3}$ \\ and WAN IRYANI WAN ISMAIL ${ }^{1 *}$ \\ ${ }^{1}$ Cell Signaling and Biotechnology (CeSBTech), Faculty of Science and Marine Environment, \\ Universiti Malaysia Terengganu, 21030 Kuala Nerus, Terengganu, Malaysia \\ ${ }^{2}$ Faculty of Pharmacy, Universiti Teknologi MARA, Puncak Alam Campus, \\ 42300 Bandar Puncak Alam, Selangor, Malaysia \\ ${ }^{3}$ Faculty of Veterinary Medicine, Universiti Putra Malaysia, \\ 43400 Serdang, Selangor, Malaysia \\ *E-mail: waniryani@umt.edu.my
}

Accepted 2 December 2020, Published online 25 December 2020

\begin{abstract}
Honey authenticity is one of the most critical honey trading issues worldwide. Fake honey (FH) represents almost $80 \%$ of the honey market in Malaysia. Apart from violating consumer's rights, FH consists of none of the beneficial nutritional value other than pure honey $(\mathrm{PH})$. Moreover, prolonged consumption of FH may cause harm to human health. However, data regarding these issues is limited. In this study, both $\mathrm{PH}$ and FH were tested using 3T3-L1 adipocytes and in high-fat diet (HFD)-induced obese Sprague Dawley rats. Initially, a physicochemical analysis was performed on both the honey samples according to the Codex Alimentarius Commission and International Honey Commission procedures. After $72 \mathrm{hr}$, PH significantly reduced lipid accumulation and triglyceride levels in the adipocytes. In the rats, low glucose, cholesterol, and triglyceride levels were significantly detected after orally administered for 16 weeks. Conversely, FH significantly induced higher lipid accumulation and triglyceride levels in adipocytes and excess high blood glucose, cholesterol, and triglyceride levels in rats. The results demonstrated that FH has negative effects on lipid metabolism, and prolonged consumption may cause health complications. Furthermore, prompt actions are required to address this problem.
\end{abstract}

Key words: Fake honey, health complications, natural honey, pure honey, obesity

\section{INTRODUCTION}

Honey is a natural sweetener that is widely used globally across cultures, religions, and socioeconomic backgrounds. In 2015, approximately 520,336 tons of honey was produced, valuing EUR 1.6 million (UN Comtrade, 2018). According to the Food and Agriculture Organization (FAO), honey production has been consistently increasing from 1980 to 2015 (UN Comtrade, 2018). However, even with a production rate of $0.23-0.24 \mathrm{~kg} /$ annum, the production is insufficient as in some countries of central Europe, for example, Austria, Germany, and Switzerland, honey consumption can reach up to $1 \mathrm{~kg} /$ annum (Bradbear et al., 2009). High demand for honey but a shortage in supply has resulted in

* To whom correspondence should be addressed. adulteration and the production of fake honey (FH). Fraudulent practices about honey production are a major problem within this industry, and currently, there is no effective solution for tackling this issue.

One of the problems that may occur from the consumption of FH is adverse effects on health. The honey consists of high fructose corn syrup or caramelized sucrose and gives little nutritional and medicinal value compare to pure honey $(\mathrm{PH})$ or natural honey (Damto et al., 2019). The consumption of these types of sugar are known to increase body weight and body fats, and long term effect may increase the risk of obesity, hypertension, heart disease and other health complications (Ko et al., 2017). However, the number of studies analyzing these effects of fake honey is scarce. In this study, we investigated the effects of one type of fake honey $(\mathrm{FH})$ and pure honey $(\mathrm{PH})$, which are available in 
our local market using 3T3-L1 adipocytes and a high-fat diet (HFD)-induced obese rats.

\section{MATERIALS AND METHODS}

\section{Honey sample preparation}

PH used in this study was raw Acacia honey, a unifloral honey that comes to the nectar from acacia tree (Acacia mangium) and collected by the Apis mellifera bee species. The honey was collected in 2012 from an Acacia apiary farm in Ulu Sedili, Johor, Malaysia. FH was purchased in the same year from a local grocery market in Selangor, Malaysia.

\section{Physicochemical analysis and antioxidant properties}

Physicochemical analysis, including moisture content, $\mathrm{pH}$, acidity, ash content, hydroxymethylfurfural (HMF) level, the presence of glucose oxidase, and sugar composition were assessed according to the procedures listed in the Codex Alimentarius Commission (CAC) (2001) and International Honey Commission (IHC) (2009). Antioxidant properties, particularly total phenolic content (TPC) and total flavonoid content (TFC) were determined using the method developed by Salleh et al. (2017).

\section{Cell culture study}

3T3-L1 cell lines (ATC.CL-173) were purchased from the American Type Culture Collection (ATCC, USA). The pre-adipocyte cells were cultured and induced to differentiate into adipocytes according to the method reported by Ismail et al. (2014). Lipid accumulation and triglyceride levels in the adipocytes were measured after treatment with $\mathrm{PH}$ and $\mathrm{FH}$ at concentrations of $0-100 \mathrm{v} / \mathrm{v}$, according to the method reported by Samat et al. (2018).

\footnotetext{
Animal study

Seven weeks old male Sprague-Dawley rats, with bodyweight ranging from 200 to $220 \mathrm{~g}$, obtained from Laboratory Facilities of Animal Management (LAFAM), Universiti Teknologi MARA (UiTM), Puncak Alam, Selangor. The rats were housed at one rat per cage and maintained under an ambient room temperature and 40-65\% relative humidity, with a 12 -hr cycle of light and dark according to Samat et al. (2014). Twenty-four rats were divided into four groups $(n=6)$ : Control, HFD, HFD + PH, and HFD + FH. The control rats were orally administered with distilled water and rodent food ad libitum. Obesity was induced in these rats by providing a HFD according to the procedure reported by Samat et al. (2017). Two groups of rats were orally fed using oral gavage with $2000 \mathrm{mg} / \mathrm{kg}$ body weight of either PH or FH daily
}

for 16 weeks. On the last day of the feeding period, a blood sample was collected and centrifuged at $4000 \mathrm{rpm}$ for $15 \mathrm{~min}$ at $4^{\circ} \mathrm{C}$. The clear serum obtained was separated and subjected to lipid profile test, consist of cholesterol, triglycerides, and glucose levels. The procedures involving animals were approved by the UiTM Ethics Committee $(05 / 2012)$.

\section{Statistical analysis}

All data are presented as the mean \pm standard deviation. Statistical analysis for cell culture studies was performed using the Sigma Plot Version 12 (Systat Software Inc., CA, USA) followed by Dunnett's posthoc tests. Data from the animal study were analyzed using one-way analysis of variance followed by the posthoc Tukey's test (SPSS version 18). The data thus obtained were then compared with those obtained for the controls. Differences with $p$-values of $p<0.05$ were considered to be statistically significant.

\section{RESULTS AND DISCUSSION}

Acacia honey was selected in the study as the pure honey sample. The honey is commercially available throughout the year compared to other honey, for instance, Tualang honey (Samat et al., 2014). Tualang honey is seasonal honey, which is only available between June-September every year. Moreover, Acacia honey is a unifloral honey, making it more reliable to standardize the honey quality and to measure its authenticity honey using physicochemical analysis (Samat et al., 2014). The health benefits of the local honey are also less reported compared to other honey samples, yet to be disclosed in this study.

The physicochemical data of $\mathrm{PH}$ were considerably different from those of $\mathrm{FH}$, particularly in terms of free acidity, ash content, HMF level, and the presence of glucose oxidase (Table 1). PH showed high free acidity value, low HMF value, and the presence of glucose oxidase and ash content. On the contrary, FH displayed the characteristic of adulterated honey with a high value of HMF and the absence of glucose oxidase. In freshly harvested honey, HMF is absent or occurs at a very low concentration, however, heat treatment or long storage conditions can increase the level of HMF (Shapla et al., 2018). In the case of fake honey production, high sugar (sugarcane syrup) content, and heat treatment caused a high level of HMF (Shapla et al., 2018). Glucose oxidase is an enzyme found in honey that catalyzes glucose to form gluconic acid and hydrogen peroxide $\left(\mathrm{H}_{2} \mathrm{O}_{2}\right)$, which are the agent responsible for antibacterial activity in honey (Hermanns et al., 2020). The authenticity 
Table 1. Physicochemical data of pure and fake honey

\begin{tabular}{lcc}
\hline Parameter & $\mathrm{PH}$ & $\mathrm{FH}$ \\
\hline Moisture Content $(\%)$ & $22.30 \pm 0.10$ & $18.70 \pm 0.02$ \\
$\mathrm{pH}$ & $3.50 \pm 0.03$ & $3.79 \pm 0.03$ \\
Free Acidity & $85.20 \pm 0.40^{*}$ & $24.00 \pm 0.05$ \\
Ash Content $(\mathrm{g})$ & $0.18 \pm 0.04$ & $\mathrm{ND}$ \\
HMF $(\mathrm{mg} / \mathrm{kg})$ & $0.68 \pm 0.03^{*}$ & $195.4 \pm 3.50$ \\
Glucose oxidase & Active & Not Active \\
\hline
\end{tabular}

Values are expressed as means $\pm \mathrm{SD}(\mathrm{n}=3) . \mathrm{PH}$ (pure honey), $\mathrm{FH}$ (fake honey), ND (not determined). ${ }^{*}$ significantly different, $p<0.05$.

Table 2. Sugar composition of pure and fake honey

\begin{tabular}{lccc}
\hline Parameter & Codex Standard & $\mathrm{PH}$ & $\mathrm{FH}$ \\
\hline Reducing Sugar (\%) & $>60$ & $70.43 \pm 3.51^{*}$ & $49.29 \pm 1.05$ \\
Fructose/Glucose ratio & 1 & $1.55 \pm 0.43^{*}$ & $0.75 \pm 0.06$ \\
Sucrose (\%) & $<5$ & $2.63 \pm 0.27^{*}$ & $5.75 \pm 0.43$ \\
\hline
\end{tabular}

Values are expressed as means $\pm \mathrm{SD}(\mathrm{n}=3)$. PH (pure honey), $\mathrm{FH}$ (fake honey). ${ }^{*}$ significantly different, $p<0.05$.

status of FH was confirmed by its sugar composition (Table 2). FH did not comply with the standards set by Codex for these components. The reducing sugar $(49.29 \pm 1.05)$, fructose/glucose ratio $(0.75 \pm 0.06)$, and sucrose composition $(5.75 \pm 0.43)$ of $\mathrm{FH}$ was not within the range.

The value of TPC and TFC of Malaysian honey varied greatly depending on the type of honey. As shown in Table 3, PH contained the highest level of TPC (186.56 $\pm 4.03 \mathrm{mg} / \mathrm{kg})$ and TFC (36.66 \pm $1.50 \mathrm{mg} / \mathrm{kg}$ ) compared to FH. The value of TPC and TFC is due to the botanical sources of honey. However, the value is considered low if compared to other pure honey since our honey sample is unifloral honey. It has been reported that multifloral honey contains higher TPC and TFC values compared to unifloral honey (Machado De-Melo et al., 2017). However, FH, which is not produced naturally by a honeybee, showed a significantly small amount of TPC and TFC value compared to the $\mathrm{PH}$.

Based on the in vitro study, $\mathrm{PH}$ significantly reduced 3T3-L1 adipocytes lipid accumulation and triglycerides level in a dose-dependent manner (Figure 1). This result suggested that $\mathrm{PH}$ inhibited adipogenesis of the adipocytes by reducing lipid accumulation, thus reducing its triglyceride content. In contrast, FH significantly increased lipid accumulation and triglyceride level in the adipocytes, which indicates that the FH may induce adipogenesis in the cells.

Similar findings were observed in vivo study, where FH exacerbated the obesity in rats from group HFD + FH. The rats have displayed a significant increment in the glucose level, which was up to two times $(28.4 \pm 2.5)$ and cholesterol level increased up to four times $(48.6 \pm 4.8)$ than rats in the HFD group. The high levels of glucose, cholesterol, and triglyceride lead to hyperglycemia and dyslipidemia, which increase the risk of obesity and its complication such as heart disease, diabetes, and cancer (Kinlen et al., 2018).

In contrast, the level of blood glucose, triglyceride, and cholesterol was significantly reduced in HFD rats fed with $\mathrm{PH}$ when compared to HFD rats fed with FH (Table 4). The results were similar to a study conducted by Samat et al. (2014), where acacia honey reduced the level of glucose, cholesterol, and triglycerides in normal diet-fed male rats. The positive effects of $\mathrm{PH}$ may be due to its high phenolic, and flavonoids content. The phenolic and flavonoid in honey mainly depend on its floral origin and can also be used as a tool for classification and authentication, especially in the case of unifloral varieties, including Acacia honey (Cianciosi et al., 2018). According to SantosBuelga and Gonzalez-Paramas (2017), the phenolic compound in pure honey is responsible for many beneficial health benefits such as antioxidant, antiinflammatory, anti-cancer, and anti-diabetic activity. Therefore, based on our results, it is suggested that PH can ameliorate obesity by the inhibition of adipogenesis in vitro and reduce levels of glucose and lipid profile in vitro. Subsequently, pure honey has the potential to be used as an alternative to reduce obesity in obese and diabetic patients. However, more studies are required to understand the mechanism and to identify the phenolic compounds, which are responsible for the effects. 
Table 3. Antioxidant properties of pure and fake honey

\begin{tabular}{lcc}
\hline Parameter & PH & FH \\
\hline TPC (mg gallic acid $/ \mathrm{kg})$ & $186.56 \pm 4.03^{*}$ & $40.93 \pm 1.10$ \\
TFC (mg catechin/kg) & $36.66 \pm 1.50^{*}$ & $14.75 \pm 1.11$ \\
\hline
\end{tabular}

Values are expressed as means $\pm \mathrm{SD}(\mathrm{n}=3)$. $\mathrm{PH}$ (pure honey), $\mathrm{FH}$ (fake honey). *significantly different, $p<0.05$.

Table 4. Glucose, triglyceride, and cholesterol levels in Sprague-Dawley rats with high-fat diet-induced obesity after being fed pure or fake honey for 16 weeks

\begin{tabular}{lcccc}
\hline Test & Control & HFD & HFD + PH & HFD + FH \\
\hline Glucose level (mmol/L) & $3.39 \pm 0.01$ & $12.55 \pm 0.52^{*}$ & $7.13 \pm 0.66$ & $28.4 \pm 2.5^{*}$ \\
Triglycerides level (mmol/L) & $2.55 \pm 0.11$ & $17.65 \pm 0.72^{*}$ & $13.73 \pm 0.61^{*}$ & $26 \pm 1.2^{*}$ \\
Cholesterol level (mmol/L) & $5.63 \pm 0.31$ & $13.67 \pm 0.50^{*}$ & $8.30 \pm 0.45$ & $48.6 \pm 4.8^{*}$ \\
\hline
\end{tabular}

HFD = high-fat diet, HFD $+\mathrm{PH}=$ rats on high-fat diet fed with pure honey, and HFD $+\mathrm{FH}=$ rats on high-fat diet fed with fake honey. Values are expressed as means $\pm \mathrm{SD}(\mathrm{n}=3)$. * significantly different, $p<0.05$.

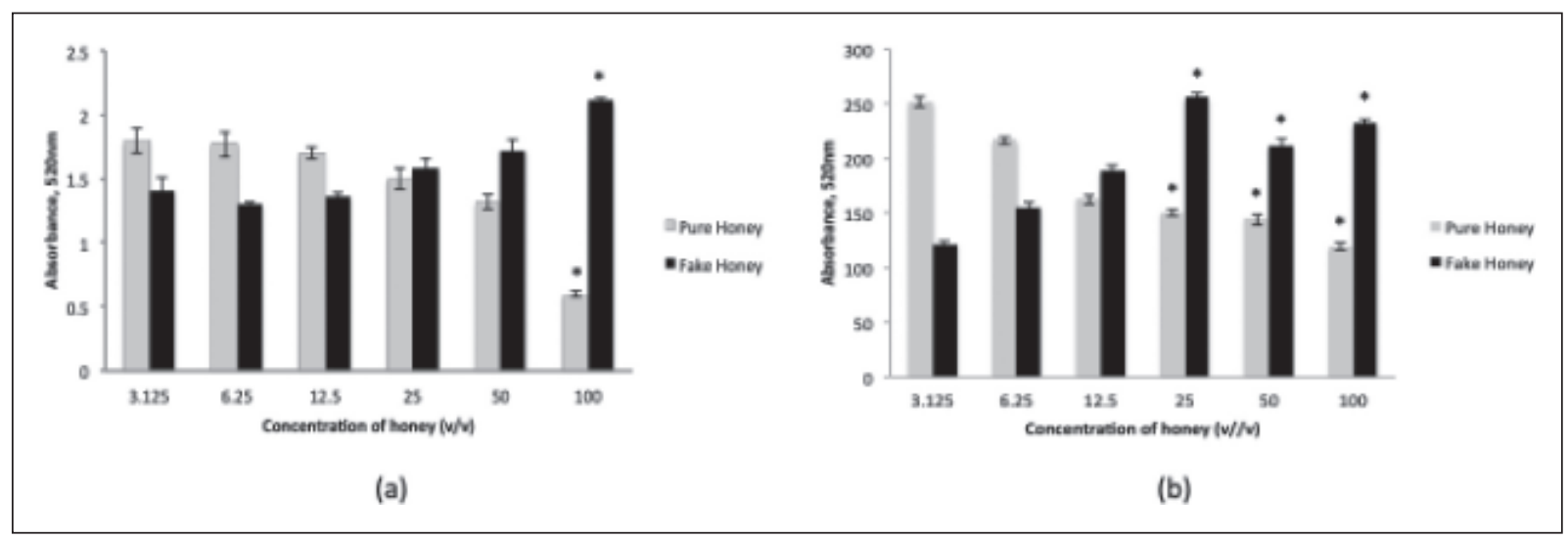

Fig. 1. Lipid accumulation (a) and triglyceride levels (b) in differentiated 3T3-L1 adipocytes treated with either pure or fake honey. Lipid accumulation was spectrophotometrically assessed after treatment with several concentrations of honey $(0$ $100 \% \mathrm{v} / \mathrm{v})$. Results are presented as the mean \pm standard deviation $(\mathrm{n}=4)$. *Significantly different compared with control $(p<0.05$, analysis of variance and Dunnett's test).

Results presented in this study are consistent with different types of pure honey reported by other studies (Chepulis et al., 2009; Nemoseck et al., 2011; Ajibola et al., 2013; Samat et al., 2018). Samat et al. (2018) reported that pineapple honey reduced the lipid droplet size and lipid accumulation of 3T3-L1 adipocytes. Another example, clover honey, another mono-floral honey was found to improve weight regulation and reduce triglycerides level in rats (Nemoseck et al., 2011). Moreover, a diet comprising of low-dose golden syrup and sucrose (some FH types are invented with sugars) increased visceral adiposity in rats (Chepulis et al., 2009; Ajibola et al., 2013). Our study used commercial FH available in a local market. The fake honey has demonstrated the negative compared to the positive effects of consuming $\mathrm{PH}$ on glucose and lipid metabolism using in vitro and in vivo models.

\section{CONCLUSION}

The study highlights differences in physicochemical analysis among $\mathrm{PH}$ and $\mathrm{FH}$ based on the established international standards set by the CAC and IHC. The analysis can identify the authenticity status of the honey. The study also shows PH can significantly reduce levels of lipid profiles in both in vitro and in vivo models. However, more studies are warranted to understand the positive effects of $\mathrm{PH}$ consumption and to confirm the adverse health effects of FH utilization. The data are crucial in providing additional justification for 
ceasing fraudulent activities in commercial honey production.

\section{ACKNOWLEDGEMENTS}

This study was financially supported by research grants from For Women in Science (FWIS): L'OréalUNESCO Fellowship (vot: 53349) and Research Entity Initiative (REI), UiTM for the project: 600RMI /DANA 5/3/REI (9/2013). We thank Mr. Mohd Ulul Ilmie Ahmad Nazri for proofreading the manuscript.

\section{REFERENCES}

Ajibola, A.W., Chamunorwa, J.P. \& Erlwanger, K.H. 2013. Comparative effect of cane syrup and natural honey on abdominal viscera of growing male and female rats. Indian Journal of Experimental Biology, 51: 303-312.

Bradbear, N. 2009. Honey Marketing and International Honey Trade in Bees and Their Role in Forest Livelihoods: A Guide to the Services Provided by Bees and the Sustainable Harvesting, Processing and Marketing of Their Products. FAO.

Chepulis, L.M. 2009. Honey versus sucrose: The impact on weight gain and other measure after short and long term feeding in rats. Functional Food for Chronic Disease (Obesity, Diabetes, Cardiovascular Disorder and Aids), 73(1): 1-7.

Cianciosi, D., Forbes-Hernández, T.Y., Afrin, S., Gasparrini, M., Reboredo-Rodriguez, P., Manna, P.P., Zhang, J., Lamas, L.B., Flórez, S.M., Toyos, P.A., Quiles, J.L., Giampieri, F. \& Battino, M. 2018. Phenolic compounds in honey and their associated health benefits: A review. Molecules, 23(9): 1-20.

Codex Alimentarius Commission: Codex Standard 1981, 12: 1-7.

Damto, T. 2019. A Review on Effect of Adulteration on Honey Properties. SSRN Electronic Journal.

Hermanns, R., Mateescu, C., Thrasyvoulou, A., Tananaki, C., Wagener, F.A.D.T.G. \& Cremers, N.A.J. 2020. Defining the standards for medical grade honey. Journal of Apicultural Research, 59(2): 125-135.

Ismail, W.I.W., King, J.A., Anwar, K. \& Pillay, T.S. 2013. Indinavir and nelfinavir inhibit proximal insulin receptor signalling and salicylate abrogates inhibition: Potential role of the NFkappa B pathway. Journal of Cellular Biochemistry, 114(8): 1729-1737.
International Honey Commission. 2009. Harmonised Methods of the International Honey Commission. Swiss Bee Research Centre, Liebefeld. Pp. 63.

Kinlen, D., Cody, D. \& O'Shea, D. 2018. Complications of obesity. QJM, 111(7): 437-443.

Ko, E., Kim, H., Kim, Y., Kim, H. \& Lee, S. 2017. Effect of high fructose corn syrup (HFCS) intake on the female reproductive organs and lipid accumulation in adult rats. Development \& Reproduction, 21(2): 151-156.

Nemoseck, T.M., Carmody, E.G., Furchner-Evanson, A., Gleason, M., Li, A., Potter, H., Rezende, L.M., Lane, K.J. \& Kern, M. 2011. Honey promotes lower weight gain, adiposity, and triglycerides than sucrose in rats. Nutrition Research, 31(1): 55-60.

Machado De-Melo, A.A., de Almeida-Muradian, L.B., Sancho, M.T. \& Pascual-Maté, A. (2018). Composition and properties of Apis mellifera honey: A review. Journal of Apicultural Research, 57(1): 5-37.

Salleh, M.A.M., Eshak, Z. \& Ismail, W.I.W. 2017. Acacia honey induces apoptosis in human breast adenocarcinoma cell lines (MCF-7). Jurnal Teknologi, 79(4): 9-16.

Santos-Buelga, C. \& Gonzalez-Paramas, A.M. 2017. Chemical Composition of Honey. In: Bee Products - Chemical and Biological Properties. J.M. Alvarez-Suarez (Ed.). Springer. pp. 43-82.

Samat, S., Salleh, M.A.M., Radzi, M.N.M., Adam, Z. \& Ismail, W.I.W. 2018. Pineapple honey inhibits adipocytes proliferation and reduces lipid droplet accumulation in 3T3-L1 adipocytes. Malaysian Applied Biology, 48(1): 21-26.

Samat, S., Enchang, F.K., Nor Hussein, F. \& Ismail, W.I.W. 2017. Four-week consumption of malaysian honey reduces excess weight gain and improves obesity-related parameters in high fat diet induced obese rats. Evidence-Based Complementary and Alternative Medicine, 2017: Article ID 1342150 .

UN Comtrade. 2008. United Nations Statistics Division [WWW Document]. URL https:// c o m t r a d e. u n.org / d b/ m r / rfCommoditiesList.asp $\mathrm{x}$ ? $\mathrm{px}=\mathrm{H} 1 \& \mathrm{cc}=0409$ (accessed 10.19.18). 
